Kai A. Konrad

\title{
Information Alliances in Contests with Budget Limits
}

Max Planck Institute for Intellectual Property,

Competition and Tax Law and WZB

SP || $2010-21$

December 2010

Research Area

Markets and Politics

Research Professorship \& Project

"The Future of Fiscal Federalism"
Schwerpunkt

Märkte und Politik

Forschungsprofessur \& Projekt

"The Future of Fiscal Federalism" 
Kai A. Konrad, Information Alliances in Contests with Budget Limits, Discussion Paper SP II 2010 - 21, Wissenschaftszentrum Berlin, 2010.

Wissenschaftszentrum Berlin für Sozialforschung $\mathrm{gGmbH}$, Reichpietschufer 50, 10785 Berlin, Germany, Tel. (030) 25491 - 0 Internet: www.wzb.eu 


\section{ABSTRACT}

\section{Information Alliances in Contests with Budget Limits}

by Kai A. Konrad *

We study the role of information exchange through alliances in a framework with contestants who have binding budget limits and know their own budget limit but are incompletely informed about other contestants' budget limits. First, we solve for the Bayesian Nash equilibrium. Then we consider the role of information exchange through alliances. Contestants learn the budget limits of all players who are within the same alliance, and then decide independently about their own contest efforts. This type of alliance formation is beneficial for alliance members and neutral for players who do not belong to the alliance. Also, a merger between alliances is beneficial for their members. Further, we consider merger between alliances and discuss the set of stable combinations of alliances.

Keywords: Contest, budget limits, incomplete information, alliances, information sharing

JEL classification: D72, D74

I thank Elias Brumm, Florian Morath and two anonymous reviewers for helpful comments. The usual caveat applies. Financial support by the German Science Foundation (DFG) is gratefully acknowledged. 


\section{Introduction}

Participants in contests are often constrained by their budgets. Their willingness to expend effort may often exceed what they are actually able to spend. If several players participate in a contest, the information about own and co-players' budget constraints is important, and the equilibrium outcome of the competition depends on the actual budgets and on the distribution of information about these budgets. In this paper we consider contests in which players are severely budget constrained, and in which the actual budget of each single player is private information. We study the role of groups of players who truthfully exchange information about their respective budgets. These groups are called "information alliances". Our main research questions are: How does the truthful mutual exchange of information about each other's budget limits within these groups affect equilibrium behavior and players' equilibrium payoffs? How does the formation of an alliance affect the payoffs of members of the alliance and how does it affect outsiders? What does this imply for the willingness to take part in the formation of an alliance? The formation of an alliance typically involves some type of closer cooperation, possibly including joint actions, exchange of personnel, use of the same information infrastructure etc. For this reason we believe that alliances cause an information transfer between the members of the same alliance. The information transfer may be a by-product, as the formation of an alliance may also have a large number of other strategic aspects. Here we focus on the information exchange aspect and restrict the role of an alliance to this aspect, allowing the alliance members to compete and fight independently.

These questions are relevant in two areas of political competition. Perhaps the most important example is military conflict. Nation states engaged in war often use their whole military capacity, rather than considering which stock of their weapons they preserve for other purposes or future wars, suggesting that they are actually budget constrained. And a nation's actual military capacity is typically not perfectly known to adversaries. ${ }^{1}$ Alliances may change the distribution of information. Weitsman (1997) argues that alliances are instruments for managing possible conflict

\footnotetext{
${ }^{1}$ Stanley Kubrick's movie Dr. Strangelove illustrates the role of information. In the movie the US launches a nuclear attack against the Soviet Union, not knowing that the Soviet Union has installed the "doomsday machine" that is automatically triggered by the attack and causes an armageddon.
} 
among the alliance members. Our analysis shows how information exchange inside the alliance can eliminate military conflict between alliance members. Bearce, Flanagan and Floros (2006) also relate the formation of alliances with information exchange more directly. They argue that alliances, by including joint defence planning, joint exercises as rehearsals and joint operations, allow for an exchange of information about various dimensions of military strength (numerical size, training, readiness, equipment etc.). They illustrate this point by case studies of the North Atlantic Treaty Organization (NATO) and other prominent military alliances. Without offering a more formal analysis, they highlight a possible causal link between this information exchange and the absence of military conflict between alliance members. Their argument rests on the established bargaining theory of military conflict, where incomplete information is identified as a key reason for failure of reaching an efficient (peaceful) outcome (see, e.g., Fearon 1995). We borrow from their piecemeal evidence about the role of alliances as institutions that facilitate information transfer among its members, but pursue a different causal link between information and the outbreak of military conflict that is more closely related to the standard economic theory of contests. In the formal analysis we rule out a bargaining stage, as successful bargaining requires the ability to commit on the bargained outcome. Our formal analysis reveals that information transmission in alliances reduces military conflict. Another prediction of our results is also in line with casual empirical observations: the process of alliance formation and the exchange of information this may imply has a tendency to end up with the smallest possible set of alliances.

Another example from the area of political science is electoral competition. The role of campaign spending, campaign contributions and the regulatory framework for electoral competition has been a focus of much research in political science. ${ }^{2}$ Candidates' campaign budgets, or a candidate's capacity for mobilizing further campaign resources may often be private information. These limits can be smaller than the amount candidates may want to expend, given what they can gain in the electoral contest. In this environment it may be beneficial to learn about competitors'

\footnotetext{
${ }^{2} \mathrm{~A}$ recent controversy on the competition effects of regulation in this area is by Stratmann and Aparicio-Castillo (2006), Lott (2006) and Stratmann and Aparicio-Castillo (2007). A recent survey is by Ashworth (2006). A formal analysis on the role of budget limits in a framework with complete information is by Che and Gale (1997).
} 
budgets, or to let them know about one's own budget. The framework studied here applies and the question of information alliances becomes relevant if more than two candidates enter into the competition.

Suppose players' budgets actually limit their maximum (non-refundable) efforts in the equilibrium. After characterizing a sufficient condition for this constraint to be binding, we consider alliances and alliance formation in this framework. We study alliances that are defined as institutions that make the members of the alliance truthfully exchange information about the budget limits of all its members. Each player remains an independent player and chooses an independent effort. Also, the prize is awarded to one of the players as a function of these individual efforts. However, players inside the alliance exchange information. This exchange may influence the strategic situation for players inside and outside this alliance. We find that an alliance of this type generally benefits the members of the alliance, whereas it has no payoff implications for non-members of the respective alliance. We allow for a partition of the set of players into multiple alliances, and we consider merger between alliances from a given partition. We find that, much like the formation of the alliance itself, the merger between alliances benefits the members of these alliances and has no payoff implications for non-members of the respective merging alliances. This result can be used for a characterization of the set of all stable alliance structures. We conclude from this analysis that information exchange about players' budget constraints or fighting power is a strong incentive for forming an alliance. In the absence of countervailing effects of the alliance, we find that the equilibrium structure of alliances has the smallest possible number of alliances.

This analysis is related to several areas of research. A considerable amount of research has been conducted on the contest without noise ("all-pay auctions"). Allpay auctions with complete information have been solved by Hillman and Riley (1989), Baye, Kovenock and deVries (1996) and Siegel (2009). Che and Gale (1997), Kvasov (2007), Roberson (2006) and Ujhelyi (2009) studied different types of budget limits in this framework, sustaining the assumption of complete information. A considerable amount of work on incomplete information in all-pay auctions exists that assumes that the incomplete information pertains to the valuation of the object or prize that is at stake, or, similarly, to players' individual unit cost of contest effort. ${ }^{3}$ We focus

\footnotetext{
${ }^{3}$ Seminal papers in this context are Glazer and Hassin (1988), Amann and Leininger (1996),
} 
on incomplete information that pertains to the players' absolute effort limits of what they possibly can expend - a problem that has received comparatively little attention. ${ }^{4}$ While we also touch upon the case in which some players expend less than their budget and others may exhaust their budget, the focus of the analysis is on the case in which all players may expend their whole budget but have a positive payoff in expectation. A key aspect of the analysis is the endogeneity of information at the stage of contest, due to the possible formation of alliances. ${ }^{5}$

This analysis is also a contribution to what is called the alliance formation puzzle. The formation of alliances is frequently observed (for instance, in the context of military conflict), whereas the theory of alliances in contests convincingly identifies several reasons why it can be expected that the formation of alliances is not beneficial for the parties who form the alliance, and benefits players who do not become members of an alliance. Esteban and Sákovics (2003) established this result in a contest with three players. They compare a contest in which the players individually choose their efforts, with a contest in which two players first team up in an alliance, making contributions that sum up to the alliance's effort. Should the alliance win the prize against the single player, the two players fight internally about who of them receives the prize. Their analysis shows that free-riding problems in the making of contributions to the effort which the alliance as a group makes, and the anticipation of effort Krishna and Morgan (1997), Clark and Riis (2000), and Moldovanu and Sela (2001, 2006), and Singh and Wittman (2001). For a recent contribution see Kovenock, Morath and Münster (2009). Within these frameworks incomplete information about competitors' valuation of the prize leads to players' bids as functions of the players' valuations which in turn leads to total bid efforts that fall short of the valuation of the prize.

${ }^{4}$ The first, and virtually only, paper addressing incomplete information about players' budget constraints in the all-pay auction is Che and Gale (1996), who compare equilibrium payoffs of the all-pay auction with the standard first-price winner-pay auction. Budget limits have attracted considerable attention, however, in other areas of economics. One example is the literature on standard winner-pay auctions. See, for instance, Benoit and Krishna (2001), Brusco and Lopomo (2008, 2009), Pitchik (2009) and Burguet and McAfee (2009).

${ }^{5}$ An endogenous choice of membership in one of several subgroups is considered in Konrad and Konvenock (2009a). They analyse a complete information framework in which players self-select into subgroups, and the members of the same subgroup compete for a limited number of identical prizes. They focus on the coordination problem when players choose the subgroup they join and consider how this coordination problem depends on the number of players, subgroups and prizes. 
costs in a future internal contest for the prize make such an alliance unattractive. The formation of alliances in situations of conflict is therefore often considered a puzzle or paradox. ${ }^{6}$ Budget constraints and the desire to overcome them by pooling efforts is one of the aspects that can make alliance formation desirable. ${ }^{7}$ Our analysis focuses on a different aspect of alliance formation and reveals information exchange to be a potentially important information incentive for alliance formation. ${ }^{8}$

The formal framework and the Bayesian Nash equilibrium are described in section 2. This section also discusses why the analysis is limited to the case in which the budget limitations are severe. Information alliances are analyzed in section 3. Merger and stability of a set of alliances are discussed in section 4 . Section 5 summarizes the results and concludes.

\section{Absence of alliance}

Consider $n$ players $i \in N=\{1, \ldots, n\}$ who compete in an all-pay contest in which the winner is awarded a prize and all other players receive no prize. Let all players value the winner prize equally at $v=1$, and let these valuations be common knowledge. ${ }^{9}$ Nature assigns a budget $m_{i}$ to each player. The budgets $m_{i}$ are independent random draws from the same probability distribution $F(m)$ with the support $[0, b]$ with $b>0$ and an expected value of $E m \equiv \int_{0}^{b} m d F(m)$. This probability distribution is common

\footnotetext{
${ }^{6}$ For a survey about alliances and alliance formation in contests, see Bloch (2009). There are only some partial results explaining why alliances may actually benefit the members of the alliance. These include Skaperdas (1998) and Tan and Wang (1997) who suggest cost synergies in alliance members' efforts, and additional strategic options as in Kovenock and Roberson (2008).

${ }^{7}$ See, e.g., Cho, Jewell and Vohra (2002) and Konrad and Kovenock (2009b). Whether or not alliances allow for pooling of alliance members' efforts depends on the institutional framework.

${ }^{8}$ Some types of information spillovers between bidders have been considered in standard auctions. In the context of standard (winner pay) first price auctions with incomplete information about bidders' procurement cost, Waehrer and Perry (2003) consider the role of merger between firms. The merger essentially eliminates the less efficient bidder and this relaxes competition. Kim and Che (2004) also consider standard (winner pay) auctions if some bidders are informed about some of their rivals' valuations of the object that is auctioned.

${ }^{9} \mathrm{We}$ could allow for some asymmetry in the valuations of the winner prize. For a range of valuations for which expending an effort that is equal to the whole own budget remains optimal, this does not change the nature of the benefit of information exchange.
} 
knowledge. In addition, all players $i$ learn their own budget limit $m_{i}$, but not the budgets of the other players. Given the incomplete information all players $i$ choose their own contest effort which is denoted as $x_{i}$. Efforts are non-negative and cannot exceed the size of the respective player's budget. These efforts must be made in full and are non-refundable, irrespective of whether the player wins or does not win the prize. The winner prize is awarded to the player who chooses the highest effort. If several players choose the same highest effort, then the prize is randomly assigned to one of them with equal probability. Player $i$ 's payoff is equal to ${ }^{10}$

$$
\pi_{i}\left(x_{1}, \ldots, x_{n}\right)=\left\{\begin{aligned}
& 1-x_{i} \text { if } i \text { wins the prize } \\
&-x_{i} \text { otherwise. }
\end{aligned}\right.
$$

We search for the equilibrium function of efforts $x_{i}\left(m_{i}\right)$ that describes the players' choices $x_{i}$ as a function of their own budget $m_{i}$. If the players' budgets are sufficiently high, the budget constraint is non-binding and the problem is turned into a fully symmetric standard all-pay auction with complete information (which is well studied). Instead, we focus on cases in which the budget is small compared to the size of the prize; and, in which, in the equilibrium, the budget constraint is binding for all players. The probability distribution $F(m)$ from which the budget constraints are chosen is assumed to be continuous on the interval $(0, b]$ and differentiable on $(0, b)$. These assumptions rule out mass points for positive values of $m$, but they are consistent with a possible mass point at $m=0$. The probability density on the interior of the support is denoted by $F^{\prime}(m)$.

The existence of a mass point at zero is important for the type of equilibrium in which the budget constraints are payoff relevant for $n>2$. Therefore it is important to note that this mass point has natural interpretations in many of the examples. Players may be unable to choose positive effort, with some probability. A communication breakdown or other exogenous shocks may prevent a country from military

\footnotetext{
${ }^{10}$ This contest success function has received considerable support as an analytical tool by an analysis by Alcalde and Dahm (2010). They show that all-pay auctions with sufficiently little noise have equilibria that are payoff equivalent to the equilibrium of the all-pay auction without noise. These encompass rent-seeking games with a high exponent in Tullock's (1980) generalized lottery contest, which have been analysed by Baye, Kovenock and de Vries (1994, 1999). Note also that similar information exchange benefits that make information alliances attractive in our formal context would emerge for many other contest success functions, provided that players' budgets are sufficiently tight to make players expend their whole budgets.
} 
mobilization in time, or the decision to mobilize may be blocked by political opposition. In political contests some candidates may drop out of a given competition, due to a scandal, due to personal problems or for other reasons.

Given these assumptions, the following can be shown:

Proposition 1 Let $(n-1)(F(m))^{n-2} F^{\prime}(m) \geq 1$ for all $m \in(0, b)$. A Bayesian Nash equilibrium exists with $x_{i}=m_{i}$. The expected ex-ante payoff of each player in this equilibrium is $(1 / n)-E m$.

Proof. Without loss of generality, consider player 1. Assume that all other players follow the equilibrium strategy. The expected payoff of player 1 as a function of $x_{1}$ is $\pi_{1}(0)=\frac{1}{n}(F(0))^{n-1} \geq 0$ for $x_{1}=0$, and $\pi_{1}\left(x_{1}\right)=\left(F\left(x_{1}\right)\right)^{n-1}-x_{1}$ for $x_{1}>0$. Hence $\lim _{x_{1} \backslash 0} \pi_{1}\left(x_{1}\right)=(F(0))^{n-1} \geq \pi_{1}(0) \geq 0$, and

$$
\frac{\partial \pi_{1}\left(x_{1}\right)}{\partial x_{1}}=(n-1)\left(F\left(x_{1}\right)\right)^{n-2} F^{\prime}\left(x_{1}\right)-1 \geq 0
$$

for all $x_{1}>0$ if $(n-1)\left(F\left(x_{1}\right)\right)^{n-2} F^{\prime}\left(x_{1}\right) \geq 1$. This shows that a corner solution $x_{i}=$ $m_{i}$ maximizes $i$ 's payoff and leads to a non-negative payoff for all possible values of $m_{i} \in[0, b]$. The expected payoff $(1 / n)-E m$ follows from the fact that all players are ex-ante symmetric and all players expend their whole budget in the equilibrium.

Proposition 1 provides a condition for which players always find it optimal to expend their entire budget; and for which, in the equilibrium, all players are budget constrained. The condition is $(n-1)(F(m))^{n-2} F^{\prime}(m) \geq 1$ and this condition is fulfilled, for instance, for cumulative distributions which have a mass point of size $F(0)=e^{-\frac{\ln (n-1)}{n-2}}$ for $n>0$ and a uniform distribution of the remaining probability mass on a sufficiently small interval $(0, b]$. Note that this equilibrium permits outcomes in which the players find out ex-post that they collectively expended more than the value of the prize. The condition (2) does not rule out that budgets $m_{i}$ in an interval close to the value of the prize have a positive probability mass. Accordingly, equilibrium outcomes may be observed in which all $n$ players have drawn a budget in the range $[1-2 \varepsilon, 1-\varepsilon]$ with $\varepsilon$ positive, but close to zero, leading to efforts that sum up to more than $n$ times $1-2 \varepsilon$.

The role of budget limits as binding constraints is particularly pronounced in the type of equilibrium in Proposition 1, that is, if the condition (2) holds. This is why we focus on the type of equilibrium in Proposition 1 when analyzing the formation 
of information alliances in later sections. If, instead, the distribution of budget limits has sufficient weight on high budget values such that (2) does not hold, this removes much of the novel aspect of this analysis and leads to equilibrium outcomes that have been studied by Che and Gale (1996). For distributions $F(m)$ which give higher weights to higher budget limits, or with further mass points for positive amounts of effort, it is much less straightforward to determine closed form solutions for the equilibrium.

Before turning to the role of alliance formation, consider briefly the nature of the equilibria if the budget constraints are less tight. For this purpose, let $F(m)$ be a distribution with support $[0, b]$ without holes and without mass points. Let $(n-1)(F(m))^{n-2} F^{\prime}(m)<1$ for all $m \in(0, b)$. It turns out that efforts $x_{i}=\min \left\{m_{i}, 1\right\}$ do not constitute an equilibrium. A Bayesian Nash equilibrium exists in which the effort choices of players are (ex-ante) distributed according to $G(x)$ with support $[0,1]$ and

$$
G(x)=\sqrt[n-1]{x} \text { for } x \in[0,1] .
$$

These two properties are proved in the Appendix. The equilibrium that is characterized by (3) is similar to the ones considered by Che and Gale (1996). In the equilibrium outcome the fact that some players may own a budget that falls short of the value of the object they are bidding for can be inconsequential for the payoffs. Intuitively, the reason why other bidders may expend small amounts of effort does not matter to a player. The low effort may occur because players cannot choose a higher effort or because their randomization across the set of their feasible effort levels given their actual budget constraints makes them choose a low effort. However, a requirement for this equilibrium is that there is a sufficiently high probability that the bidders are able to make a bid to generate a bid distribution (3). The result also shows that the positive expected payoff drops to zero if the budget limits are sufficiently relaxed for a sufficiently large share of the players. Even though a player may know that the other contestants are likely to be constrained and unable to choose effort with a cost up to the value of the prize, a player with a large budget cannot benefit from this, as the player does not know whether the other contestants are actually more constrained or not. ${ }^{11}$

\footnotetext{
${ }^{11}$ The condition (2) and the condition for which equilibria of type (3) emerge leave considerable ground uncovered. A case in which the two conditions are "tight" is for $n=2$ if $F(m)$ is a uniform
} 
We focus on equilibria in which the budget constraint is generally binding. It has been explained in the introduction why this may be a highly relevant case for many all-pay contests in which the prize that is at stake is a discounted present value of future incomes or benefits, whereas the effort must be mobilized from what is currently available (with military conflict or international war as prototypical examples).

\section{Information alliances}

We now turn to alliances. An alliance is defined here as an information-sharing device: members of the same alliance know the actual budget constraints of all other members of their alliance before each player chooses his effort. There may be several alliances. But at this stage the grand alliance that encompasses all players is ruled out and discussed later.

More formally, suppose there is a partition of the set $N$ of all $n$ players into $r \geq 2$ non-empty subgroups $A_{1}, \ldots A_{r}$ with numbers of members $n_{1}, \ldots, n_{r}$. These groups are called alliance 1 , alliance 2 etc. Suppose that all the members of each of these subgroups share their private information about their own budget limits with the other members of their alliance. The partition $\mathcal{A} \equiv\left\{A_{1}, \ldots, A_{r}\right\}$ and the information exchange inside alliances is also common knowledge. In order to compare the outcome for different players and different partitions with the results in section 2 , we define players who are in a subgroup which consists of just this player as stand-alone players. Further, the information asymmetry between players from different alliances remains as in section 2: for players from different alliances only the distribution $F(m)$ is common knowledge. Note that in this framework an alliance is not a vehicle to add or compound the efforts of several players to a group's mega-effort that may then beat the rivals or rival groups. ${ }^{12}$ Further, while the formation of an alliance may generate an additional surplus to its members, or may generate a cost, the formation

distribution on $[0, b]$.

${ }^{12}$ We also disregard a possible wasteful conflict about the distribution of the prize among alliance members here. As has been highlighted by Esteban and Sákovics (2003) and Garfinkel (2004), the possibility of wasteful internal fights about the distribution of a prize inside the alliance can be a major drawback to the formation of alliances. For a comprehensive survey that considers alliances with and without intra-alliance conflict, see Bloch (2009). 
of an alliance is assumed to be cost neutral here. ${ }^{13}$ The existence of an alliance is also neutral to the allocation rule: each player remains a single player and an independent decision maker, and the winner prize is allocated among individual contestants, as a function of their individual effort choices. However, as a member of an alliance the player shares his and the other alliance members' private information about their budget limits (in terms of their individual maximum feasible efforts). All players learn about which alliances exist. And when choosing their efforts they take the existence of information sharing in these other alliances into consideration.

To characterize a Bayesian Nash equilibrium that corresponds to the equilibrium in Proposition 1 and to compare the payoffs of players in the world without, and with information alliances we define the interim payoff of player $i$ : The interim payoff is the expected payoff of this player after learning his own budget limit but prior to learning the budget limits of other players.

Proposition 2 Let the condition

$$
\left(n-n_{k}\right)\left(F\left(x_{i}\right)\right)^{n-n_{k}-1} F^{\prime}\left(x_{i}\right) \geq 1
$$

hold for all $x_{i} \in(0, b)$ for all $k=1, \ldots, r$. (i) A Bayesian Nash equilibrium exists with $x_{i}=m_{i}$ if $m_{i}=\max \left\{m_{s} \mid s \in A_{k}\right\}$ and $x_{i}=0$ if $m_{i}<\max \left\{m_{s} \mid s \in A_{k}\right\}$ for all $i \in A_{k}$, for all alliances $A_{k}$ with $k=1, \ldots, r$. (ii) Let $i$ be a player with budget $m_{i}$. Consider the two partitions $\mathcal{A}=\left\{A_{1}, \ldots, A_{h}, A_{k}, \ldots A_{r}\right\}$ and and $\mathcal{A} \prime=\left\{A_{1}^{\prime}, \ldots, A_{h} \cup A_{k}, \ldots, A_{r}^{\prime}\right\}$. Let (4) hold for all alliances in both partitions. Let player $i \in A_{k}$ in both partitions. The interim payoff of player $i$ is higher (the same) in $\mathcal{A}$ ' than (as) in $\mathcal{A}$ if $m_{i}>0$ (if $m_{i}=0$ ).

Proof. (i) Suppose that all other players $j \neq i$ follow the strategy described in the candidate equilibrium. Consider $i \in A_{k}$ in the candidate equilibrium. If $m_{i}<$ $\max \left\{m_{s} \mid s \in A_{k}\right\}$, then $x_{i}=0$ is superior to any positive $x_{i}$ as it increases $i$ 's payoff by $x_{i}$, compared to any $x_{i}>0$. If, instead, $m_{i}=\max \left\{m_{s} \mid s \in A_{k}\right\}$, two cases need

\footnotetext{
${ }^{13}$ Suppose joining an alliance causes a fixed cost upfront. If player $i$ joins a particular alliance $A_{r}$, this may cause a change in the beliefs of players who are not members of $A_{r}$ about $i$ 's budget. Similarly, if a player does not join an alliance, this may be because his budget is too small to cover the fee, or because he has a very high budget. In any case, the appropriate equilibrium concept changes from Bayesian Nash to Perfect Bayesian Nash equilibrium.
} 
to be distinguished. If $m_{i}=0$, then player $i$ has no choice, and $x_{i}=m_{i}=0$ is optimal. If $m_{i}>0$, then with probability 1 there is no other member of alliance $A_{k}$ who has the same budget. Accordingly, in the candidate equilibrium, all other members of the alliance $A_{k}$ choose zero efforts. Consider the payoff of player $i$ from choosing $x_{i} \in\left(0, m_{i}\right)$. The probability that player $i$ wins with this effort is equal to the probability that $x_{i}$ is larger than the largest budget in any of the other alliances, and this is the same probability as the probability that all players who are not a member of $A_{k}$ have a lower budget than $x_{i}$. This probability is equal to $\left(F\left(x_{i}\right)\right)^{n-n_{k}}$. Accordingly, player $i$ 's payoff is

$$
\pi_{i}\left(x_{i}\right)=\left(F\left(x_{i}\right)\right)^{n-n_{k}}-x_{i}
$$

This payoff is (weakly) increasing in the whole range $(0, b)$ if

$$
\frac{\partial \pi_{i}\left(x_{i}\right)}{\partial x_{i}}=\left(n-n_{k}\right)\left(F\left(x_{i}\right)\right)^{n-n_{k}-1} F^{\prime}\left(x_{i}\right)-1 \geq 0
$$

in this range. Hence, the condition

$$
\left(n-n_{k}\right)\left(F\left(x_{i}\right)\right)^{n-n_{k}-1} F^{\prime}\left(x_{i}\right) \geq 1 \text { for all } x_{i} \in(0, b)
$$

is sufficient for making $x_{i}=m_{i}$ a choice that maximizes this player's payoff.

(ii) Let the number of members of alliances $A_{h}$ and $A_{k}$ be $n_{h} \geq 1$ and $n_{k} \geq 1$, respectively. If $m_{i}=0$, then $x_{i}=0$ and $i$ 's interim payoff is $\frac{1}{n}\left(F\left(m_{i}\right)\right)^{n-1}$ for both partitions $\mathcal{A}$ and $\mathcal{A}^{\prime}$. If $m_{i}>0$, then $i$ wins the prize with a probability $\left(F\left(m_{i}\right)\right)^{n-1}$ for both partitions $\mathcal{A}$ and $\mathcal{A}^{\prime}$. However, if partition $\mathcal{A}$ prevails, then $i$ expends a positive effort $x_{i}=m_{i}$ if and only if $m_{i}=\max \left\{m_{s} \mid s \in A_{k}\right\}$ (and $x_{i}=0$ otherwise), and if partition $\mathcal{A}^{\prime}$ prevails, then $i$ expends a positive effort $x_{i}=m_{i}$ if and only if $m_{i}=\max \left\{m_{s} \mid s \in A_{h} \cup A_{k}\right\}$ (and $x_{i}=0$ otherwise). ${ }^{14}$ Accordingly, as for a given $m_{i}$ the probability that $i$ has the highest budget inside its alliance is decreasing in the number of members of the alliance, the probability that $i$ expends positive effort is lower for partition $\mathcal{A}^{\prime}$. Note also that the win probabilities do not depend on the particular partition, and the probability for expending positive effort $x_{i}=m_{i}$ depends only on the size of $m_{i}$, on $F(m)$ and on the number of players who are inside the same

\footnotetext{
${ }^{14}$ Note that all events with $\max \left\{m_{s} \mid s \in A_{h}\right\}=\max \left\{m_{s} \mid s \in A_{k}\right\}>0$ constitute a set of events that has zero probability exogenously (and independently of players' actions in previous stages), which is why we do not have to define equilibrium strategies for this set of events.
} 
alliance with $i$, but not on how the players who are not members of this alliance are partitioned into other alliances.

Proposition 2 characterizes an equilibrium in which the player with the highest budget from each alliance chooses an effort that is precisely equal to his budget, and all players from the same alliance who have a lower budget abstain from making any effort. The equilibrium has a simple intuition. Players inside an alliance $A_{k}$ share their information about their respective budgets. After having made this comparison, typically, unless they all have zero budgets, it becomes clear to $n_{k}-1$ of them that there is a player in their group who has a larger budget than the others and that this player will choose higher effort than they can. They can use the information and withdraw from competition, i.e., not expend positive effort. All the alliance members who decide to quit save their efforts. From the point of view of non-members, these withdrawals are irrelevant for their effort choice, as the players who quit are not the ones with the highest budgets. For the competition only the highest effort from the players inside the alliance matters; and the distribution of this highest effort is unaffected by all the alliance members' lower efforts, whether they are zero or positive. The proposition also shows that the information exchange that takes place in alliances reduces the total effort, and that the members of the alliance are the only beneficiaries of these savings.

\section{Merger incentives and stability}

To consider the incentives for contestants for a merger between alliances we need to describe the timing of the information-sharing in this case. We distinguish between two cases as regards this timing that are both plausible. In one case (CASE 1) the process of possible mergers is completed before players mutually reveal the size of their budget among the alliance members. Alternatively, (CASE 2) the alliance members learn about the budgets of the other members of their alliance prior to a possible further merger with another alliance. If they merge with another alliance, the members of both alliances also learn the budget constraints of the members of the merging alliances immediately after the merger, and all intra-alliance information exchange is completed prior to choosing their own efforts in the all-pay auction.

Proposition 3 Let there be a partition of the set $N$ of all $n$ players into $r \geq 3$ 
alliances $\left\{A_{1}, \ldots, A_{r}\right\}$ with numbers of members $n_{1}, \ldots, n_{r}$. Consider a merger of two of these alliances $A_{h}$ and $A_{k}$ with numbers $n_{h}$ and $n_{k}$ of members that leads to a new alliance $A_{h \& k}$ with $n_{h}+n_{k}$ members. Let condition (7) also hold for $n_{h \& k}=n_{h}+n_{k}$. The merger (weakly) increases the interim payoffs of all members of $A_{h}$ and $A_{k}$ in CASE 1. In CASE 2, consider the expected payoffs of players $i_{h} \in A_{h}$ who know their own budget and the budgets of the members of $A_{h}$. The merger leaves these payoffs of all players $i_{h} \in A_{h}$ with $m_{i_{h}} \neq \max \left\{m_{s} \mid s \in A_{h}\right\}$ unchanged and increases (leaves unchanged) the expected payoff for $i_{h} \in A_{h}$ with $m_{i_{h}}=\max \left\{m_{s} \mid s \in A_{h}\right\}$ if $m_{i_{h}}>0$ (if $m_{i_{h}}=0$ )(and analogously for $A_{k}$ ).

Proof. To compare the payoffs, without loss of generality we consider a player $i$ from alliance $A_{h}$. We need to distinguish between the two cases.

Case 1 holds as a corollary to Proposition 2.

CASE 2. Consider a player $i \in A_{h}$ who learned his own budget and the budget of the members of $A_{h}$. If $m_{i}<\max \left\{m_{s} \mid s \in A_{h}\right\}$ then $i$ 's expected payoff at this point is zero, irrespective whether a merger occurs or not. If $m_{i}=\max \left\{m_{s} \mid s \in A_{h}\right\}$, then several cases need to be distinguished. If $m_{i}=\max \left\{m_{s} \mid s \in A_{h}\right\}=0$ then $x_{i}=0$ and $i$ 's probability of winning the prize after learning $m_{i}=\max \left\{m_{s} \mid s \in A_{h}\right\}$ but prior to the merger is $\frac{1}{n}(F(0))^{n-n_{h}}$ and independent of whether the merger takes place. If $m_{i}=\max \left\{m_{s} \mid s \in A_{h}\right\}>0$ then $i$ wins the prize with probability $\left(F\left(m_{i}\right)\right)^{n-n_{h}}$, with or without the merger. However, $i$ 's expected effort is lower if the merger occurs: without a merger, $i$ expends $x_{i}=m_{i}$. With the merger, $i$ expends $x_{i}=m_{i}$ if only if $m_{i}=\max \left\{m_{s} \mid s \in A_{h \& k}\right\}$ and $x_{i}=0$ otherwise.

Proposition 3 characterizes the payoff implications of a merger of alliances. The proposition shows that a merger of alliances is beneficial for the members of both alliances (or at least does not harm them), and the merger does not benefit players who are not members of the merging alliances. This result emerges for both timings of information exchange in the process of mergers of alliances. Intuitively, if two alliances merge, the information exchange is extended towards the members of both alliances. For $\max \left\{m_{s} \mid s \in A_{h}\right\}>0$ and $\max \left\{m_{s} \mid s \in A_{k}\right\}>0$, without the merger the player from each of the two alliances who has the largest budget in this alliance expends effort equal to his entire budget. Only one of them can win. If the players know about each other's budget limits, one of them will abstain from expending a positive effort, knowing that he cannot win against the other player. This 
information exchange occurs due to the merger, and prior to the choices of efforts. The merger reduces the total expected effort of all alliance members. However, it leaves the highest effort from players in the merged group unaffected. Given the (also unchanged) effort choices of players outside the two merging alliances, the merging alliance as a whole has the same overall win probability, but expends lower effort.

We can now use the results in Proposition 2 to briefly discuss the stability of a partition of the set of all players into information alliances. We continue distinguishing between CASE 1 and CASE 2 regarding the timing of information exchange. Recall that in CASE 1 we assume that players inside an alliance do not learn the budget constraints of the other players in the same alliance until a possibly endogenous process of mergers comes to a complete halt and no further possible mergers are allowed. In CASE 2 we assume that players learn about the budget constraints of other members of the same alliance as soon as an alliance is formed, irrespective whether the merging alliances $A_{h}$ and $A_{k}$ are singletons or are alliances with more than one player. We define a partition $\left\{A_{1}, \ldots, A_{k}\right\}$ as a stable partition if it has the following property:

(S1) Given $\mathcal{A} \equiv\left\{A_{1}, \ldots, A_{k}\right\}$, there are no two alliances $A_{h} \in \mathcal{A}$ and $A_{k} \in \mathcal{A}$ for which the merger of the two alliances to $A_{h \& k}=A_{h} \cup A_{k}$ is a (weak) Pareto improvement for the members of both alliances.

The stability criterion (S1) requires that, at the point at which the merger may be enacted, all members in an alliance (at least weakly) prefer non-merger to merger, for all possible mergers. We will consider the situation in which the grand coalition $(\mathcal{A}=\{N\})$ is ruled out, and a situation in which the grand coalition is feasible. We find the following:

Proposition 4 Suppose a grand coalition $(\mathcal{A}=\{N\})$ is not feasible. If the condition $\left(n-n_{k}\right)\left(F\left(x_{i}\right)\right)^{n-n_{k}-1} F^{\prime}\left(x_{i}\right) \geq 1$ holds for all $n_{k}<n-1$, then the set of stable partitions is equal to the set of partitions with only two alliances $\left\{A_{1}, A_{2}\right\}$.

Proof. Consider CASE 1. A proof is by contradiction. For any partition $\left\{A_{1}, \ldots, A_{r}\right\}$ with $r>2$ it follows from Proposition 2 that a merger between two of these alliances (weakly) increases the interim payoffs of all members of these two alliances and leaves the interim payoffs of non-members of the merging alliances unchanged. 
Consider CASE 2. All players $i$ in an alliance $A_{h}$ for which $m_{i}<\max \left\{m_{s} \mid s \in A_{h}\right\}$ have a payoff equal to zero, irrespective of whether the alliance merges with another alliance or not. Player $i$ with $m_{i}=\max \left\{m_{s} \mid s \in A_{h}\right\}$ is indifferent as regards a merger if $m_{i}=0$. For $m_{i}>0$, having learned his own budget and the budgets of other members of $A_{h}$, the player $i$ strictly benefits in expectation from a merger with another alliance $A_{k}$. After a merger it is revealed to $i$ whether $m_{i}=\max \left\{m_{s} \mid s \in A_{h}\right\}>$ $\max \left\{m_{s} \mid s \in A_{k}\right\}$ or not. The merger does not change $i$ 's probability of winning, but makes $i$ save the futile effort $m_{i}$ in case $\max \left\{m_{s} \mid s \in A_{h}\right\}<\max \left\{m_{s} \mid s \in A_{k}\right\}$.

Proposition 4 shows that the process of merger between alliances is Pareto improving as long as a further merger is possible. Intuitively, alliance members exchange information in order to prevent futile effort in an all-pay auction. This is a strong incentive for a merger, if the merger provides the means for this information exchange. We have not analyzed the precise path of possibly endogenous mergers, or the dynamics of possible merger proposals and acceptances. If the game is extended in this direction, players may choose their proposals / acceptances strategically, and their choices can be interpreted by others, and thereby may induce a change in players' beliefs about other players' budgets. This changes the nature of the game and the equilibrium concept that needs to be applied becomes Perfect Bayesian Equilibrium. Also, individual players do not have an option to switch from one alliance to another here. The option to leave one alliance and to move to another alliance is a relevant issue. Individuals' preferences would be to be allocated to a large, rather than to a small alliance.

So far the grand alliance was excluded. Consider now the payoff consequences of the formation of a grand alliance, compared to a partition with two alliances.

Proposition 5 Consider a partition of the type $\left\{A_{1}, A_{2}\right\}$ and a grand alliance $N \equiv$ $A_{1} \cup A_{2}$. The transition to the grand alliance is a (weak) Pareto improvement for players for both CASE 1 and CASE 2.

Proof. With one grand information alliance that includes all players, several situations have to be distinguished that lead to different types of equilibrium. If $m_{i}=0$ for all $i \in N$, then all players expend zero effort and win with the same probability of $1 / n$. If $m_{i}>0$ for exactly one $i \in A_{1} \cup A_{2}$ and $m_{j}=0$ for all other $j \neq i$, then $x_{j}=0$ for all $j \neq i$. The optimal effort by $i$ is not well defined in this case due to an open- 
ness problem. But a solution to this is a tie-breaking rule for $x_{i}=x_{j}=0$ by which $i$ (the only player who could expend positive effort) wins with probability 1 even if all players choose the same effort of zero, yielding an equilibrium with $x_{i}=x_{j}=0$ for all players. Finally, let

$$
m_{i}=\max \left\{m_{s} \mid s \in N\right\}>m_{j}=\max \left\{m_{s} \mid s \in N-\{i\}\right\}>0
$$

for players $i$ and $j$. Then the results in Che and Gale (1997) can be used. Their results imply that an equilibrium exists in which all players other than $i$ and $j$ expend zero effort and have a payoff of zero, the players $i$ and $j$ randomize on the interval $\left[0, m_{j}\right]$, and have expected payoffs equal to $1-m_{j}$ for player $i$ and equal to zero for player $j$ in the equilibrium. ${ }^{15}$

Consider whether players prefer the transition to the grand alliance to take place or not. We distinguish again between the two cases of timing as regards information exchange.

CASE 1: Players know only the size of their own budgets prior to a possible transition to the grand coalition. A player $i \in A_{1}$ with $m_{i}=0$ has an interim payoff equal to $\frac{1}{n}(F(0))^{n-1}$ with and without a merger. Consider the interim payoff of a player $i \in A_{1}$ with $m_{i}>0$. If the grand alliance is formed, his payoff is zero if $m_{i}<\max \left\{m_{s} \mid s \in N\right\}$. For given $m_{i}>0$ this happens with a probability of $1-\left(F\left(m_{i}\right)\right)^{n-1}$. With the remaining probability $\left(F\left(m_{i}\right)\right)^{n-1}$ his budget is $m_{i}=$ $\max \left\{m_{s} \mid s \in N\right\}$. In this case $i$ earns the payoff in the respective all-pay auction, and this payoff becomes $1-\max \left\{m_{s} \mid s \in N-\{i\}\right\}>1-m_{i}$. Accordingly, $i$ 's interim payoff exceeds $\left(F\left(m_{i}\right)\right)^{n-1}\left(1-m_{i}\right)$ by the first inequality in (8). Without formation of the grand coalition, $i$ 's interim payoff is $\left(F\left(m_{i}\right)\right)^{n-1}-\left(F\left(m_{i}\right)\right)^{n_{1}-1} m_{i}$, which is smaller than $\left(F\left(m_{i}\right)\right)^{n-1}\left(1-m_{i}\right)$.

CASE 2: Players learn their own budgets and the budgets of other members of their alliance prior to the possible formation of the grand alliance. Without loss of generality we consider again player $i \in A_{1}$. If $m_{i}<\max \left\{m_{s} \mid s \in A_{1}\right\}$ then this player anticipates at this point that his payoff is zero, with or without the formation of the

\footnotetext{
${ }^{15}$ The results in Che and Gale (1997) refer to the case in which there are only two players. It is straightforward to show that an optimal reply to the equilibrium bid distributions for $i$ and $j$ for players with a budget lower than $m_{j}$ is to bid zero, and the analysis here is based on the assumption that the grand alliance plays this equilibrium. Other equilibria, in which more than two players make positive bids, can also exist.
} 
grand alliance. Let $m_{i}=\max \left\{m_{s} \mid s \in A_{1}\right\}$. If this $m_{i}=0$, then player $i$ 's expected payoff at this point is $\frac{1}{n}(F(0))^{n-n_{1}}$, with or without the merger. If this $m_{i}>0$, then $i$ 's expected payoff at this point is $\left(F\left(m_{i}\right)\right)^{n-n_{1}}-m_{i}$ if the grand alliance is not formed. If the grand alliance is formed, player $i$ 's payoff at the point at which he knows the budgets of all members of $A_{1}$, but not those of $A_{2}$ is $\left(F\left(m_{i}\right)\right)^{n-n_{1}}(1-$ $\left.E_{m_{i}}\left(\max \left\{m_{s} \mid s \in N-\{i\}\right\}\right)\right)$, where $E_{m_{i}}\left(\max \left\{m_{s} \mid s \in N-\{i\}\right\}\right)$ is defined as the expected value of the second highest budget in $N$, conditional on $m_{i}$ being the highest budget. A comparison of these payoffs shows that player $i$ has a preference for the formation of the grand alliance.

Proposition 5 establishes that the grand coalition would be a further Pareto improvement at the interim stage. Intuitively, also the transition from a partition $\left\{A_{1}, A_{2}\right\}$ to the grand alliance does not change the payoffs of most of the players who actually have zero payoff in any case, but it yields some savings in futile effort among the players with high budgets. ${ }^{16}$ We find: if the grand alliance is feasible, endogenous alliance formation does not stop at a partition with two alliances.

\section{Conclusions}

When competing for a prize, players may often like to expend more effort than they are able to expend. Also, players may know their own limits, but typically do not know the budget limits of their competitors. This incomplete information together with tight budget constraints may lead to a Bayesian Nash equilibrium in which each player simply expends his whole budget. The total sum of effort costs expended does not exceed the value of the prize in this equilibrium in expectation, but in the equilibrium many players make futile efforts. Players would abstain from expending effort if they knew that other players are less budget constrained and can simply outbid them. Therefore, players may be interested in forming groups for the purpose

\footnotetext{
${ }^{16}$ The argument is slightly more complex than for alliance mergers in Proposition 4: due to the different nature of the contest equilibrium in the grand alliance, the players expending positive effort after the formation of the grand alliance are not necessarily a subset of the players who expended positive effort in the contest with two alliances. The formation of the grand alliance mobilizes the two players with the highest budgets, and these may well be from the same alliance $A_{1}$ or $A_{2}$. However, as this mobilized player with the second-highest budget has zero expected payoff also in the contest with a grand alliance, this does change the result.
} 
of information exchange among group members. We showed that this type of alliance formation benefits all players who join in such an alliance ex-ante, and does not harm them ex-post. We also showed that the benefits of an information alliance are typically higher if the alliance has more members, making larger alliances and the merger of alliances advantageous for members of the existing alliances. Also, such information alliances do not benefit non-members of a respective alliance. These properties can also be used to explain why the endogenous formation of alliances leads to partitions with the smallest feasible number of alliances.

In the framework considered, the formation of alliances has only the purpose of information sharing, whereas alliances typically include more features in addition to an exchange of information about strength. This makes it difficult to test the empirical predictions of our analysis directly. However, it is interesting to observe that the result by which the smallest number of alliances is desirable fits well with the observed number of alliances in international conflicts that involved many nations.

The results in this paper may contribute to explaining why alliances are formed. Alliances may alleviate information problems among players and give its members superior information about each other. It may mean that its members share information that is otherwise private, and remains private vis-a-vis players who are not members of the alliance. We show that information sharing provides a strong incentive for the formation of alliances when budget constraints are sufficiently tight. This beneficial aspect of alliance formation may outweigh some of the aspects that establish the alliance formation puzzle and may contribute to the explanation why alliances are rather common, despite the problems of free-riding and fighting inside the alliance.

\section{Appendix}

Let $F(m)$ be a distribution with support $[0, b]$ without holes and without mass points. Let $(n-1)(F(m))^{n-2} F^{\prime}(m)<1$ for all $m \in(0, b)$. We show that (i) efforts $x_{i}=$ $\min \left\{m_{i}, 1\right\}$ do not constitute an equilibrium and that (ii) a Bayesian Nash equilibrium exists in which the efforts of players are (ex-ante) distributed according to $G(x)$ as in (3).

Consider (i). As $F(m)$ has has support $[0, b]$ and has no holes and no mass 
point, this implies that $b>1$. Suppose $x_{j}=\min \left\{m_{j}, 1\right\}$ for all $j \neq i$. The payoff of $i$ is $\pi_{i}\left(x_{i}\right)=\left(F\left(x_{i}\right)\right)^{n-1}-x_{i}$ for the interior range $x_{i} \in\left(0, \min \left\{m_{i}, 1\right\}\right)$. In this range it holds that

$$
\frac{\partial \pi_{i}\left(x_{i}\right)}{\partial x_{i}}=(n-1) F^{n-2} F^{\prime}\left(x_{i}\right)-1<0 .
$$

For any given $x_{i} \in\left(0, \min \left\{m_{i}, 1\right\}\right)$, player $i$ can increase the own payoff by a decrease in $x_{i}$. Consider now (ii). The payoff of a player $i$ in the candidate equilibrium with $G_{j}\left(x_{j}\right)=\sqrt[n-1]{x_{j}}$ for all $j \neq i$ is $\pi_{i}(x)=\left(\sqrt[n-1]{x_{i}}\right)^{n-1}-x_{i}=0$. This makes the player indifferent for all possible $x_{i} \in\left[0, \min \left\{m_{i}, 1\right\}\right]$, and makes any randomization on the feasible interval $\left[0, \min \left\{m_{i}, 1\right\}\right]$ of feasible effort choices an optimal reply for player $i$. It is, therefore, sufficient to show that a random distribution of effort choices as $G(x)=\sqrt[n-1]{x}$ for the whole interval $[0,1]$ is feasible from an ex-ante point of view, given that $m_{i}$ itself is a draw from a random distribution with cumulative distribution function $F(m)$. For this purpose it is sufficient to show that $G_{j}\left(x_{j}\right)=\sqrt[n-1]{x_{j}}$ is feasible for $F(m)$ with $F(0)=0$ and $(n-1)(F(m))^{n-2} F^{\prime}(m)<1$. The latter follows from the fact that

$$
(n-1)(G(x))^{n-2} G^{\prime}(x)=1>(n-1)(F(m))^{n-2} F^{\prime}(m) .
$$

\section{References}

[1] Alcalde, J., and M. Dahm, 2010, Rent seeking and rent dissipation: a neutrality result, Journal of Public Economics, 94(1-2), 1-7.

[2] Amann, E., and W. Leininger, 1996, Asymmetric all-pay auctions with incomplete information: The two-player case, Games and Economic Behavior, $14(1), 1-18$.

[3] Ashworth, S., 2006, The economics of campaign finance. In L. Blume \& S. Durlauf (Eds.), The new Palgrave Dictionary of economics (2nd edn). Palgrave: Macmillan.

[4] Baye, M.R., D. Kovenock, and C.G. de Vries, 1994, The solution to the Tullock rent-seeking game when $\mathrm{R}>2$ : mixed-strategy equilibria and mean dissipation rates, Public Choice, 81(3-4), 289-294.

[5] Baye, M.R., D. Kovenock, and C.G. de Vries, 1996, The all-pay auction with complete information, Economic Theory, 8(2), 291-305. 
[6] Baye, M.R., D. Kovenock, and C.G. de Vries, 1999, The incidence of overdissipation in rent-seeking contests, Public Choice, 99(3-4), 439-454.

[7] Benoit, J.P., and V. Krishna, 2001, Multiple-object auctions with budget constrained bidders, Review of Economic Studies, 68(1), 155-179.

[8] Bearce, D.H., K.M. Flanagan, and K.M. Floros, 2006, Alliances, internal information, and military conflict among member-states, International Organization, 60(3), 595-625.

[9] Bloch, F., 2009, Endogenous formation of alliances in conflicts, unpublished manuscript, Ecole Polytechnique, Palaiseau.

[10] Brusco, S., and G. Lopomo, 2008, Budget constraints and demand reduction in simultaneous ascending-bid auctions, Journal of Industrial Economics, 56(1), 113-142.

[11] Brusco, S., and G. Lopomo, 2009, Simultaneous ascending auctions with complementarities and known budget constraints, Economic Theory, 38(1), 105-125.

[12] Burguet, R., and R.P. McAfee (2009), License prices for financially constrained firms, Journal of Regulatory Economics, 36(2), 178-198.

[13] Che Y.-K., and I. Gale, 1996, Expected revenue of all-pay auctions and firstprice sealed-bid auctions with budget constraints, Economics Letters, 50(3), 373-379.

[14] Che, Y.-K., and I. Gale, 1997, Rent dissipation when rent seekers are budget constrained, Public Choice, 92(1-2), 109-126.

[15] Cho, I.-K., K. Jewell, and R. Vohra, 2002, A simple model of coalitional bidding, Economic Theory, 19(3), 435-457.

[16] Clark, D.J., and C. Riis, 2000, Allocation efficiency in a competitive bribery game, Journal of Economic Behavior and Organization, 42(1), 109-124.

[17] Esteban, J., and J. Sákovics, 2003, Olson vs. Coase: Coalitional worth in conflict, Theory and Decision, 55(4), 339-357.

[18] Fearon, J.D., 1995, Rationalist explanations for war, International Organization, $49(3), 379-414$. 
[19] Garfinkel, M.R., 2004, On the stability of group formation: Managing the conflict within, Conflict Management and Peace Science, 21(1), 43-68.

[20] Glazer, A., and R. Hassin, 1988, Optimal contests, Economic Inquiry, 26(1), 133-143.

[21] Hillman, A.L., and J.G. Riley, 1989, Politically contestable rents and transfers, Economics and Politics, 1(1), 17-39.

[22] Kim, J., and Y.-K. Che, 2004, Asymmetric information about rivals' types in standard auctions, Games and Economic Behavior, 46(2), 383-397.

[23] Konrad, K.A., and D. Kovenock, 2009a, The lifeboat problem, CEPR Discussion Papers No. 7424.

[24] Konrad, K.A., and D. Kovenock, 2009b, The alliance formation puzzle and capacity constraints, Economics Letters, 103(2), 84-86.

[25] Kovenock, D., F. Morath, and J. Münster, 2009, Information sharing in contests, unpublished manuscript, WZB Berlin.

[26] Kovenock, D., and B. Roberson, 2008, Coalitional Colonel Blotto games with application to the economics of alliances, Discussion Paper SP II 2008-02, WZB Berlin.

[27] Krishna, V., and J. Morgan, 1997, An analysis of the war of attrition and the all-pay action, Journal of Economic Theory, 72(2), 343-62.

[28] Kvasov, D., 2007, Contests with limited resources, Journal of Economic Theory, 136(1), 738-748.

[29] Lott, J.R., 2006, Campaign finance reform and electoral competition, Public Choice, 129(3-4), 263-300.

[30] Moldovanu, B., and A. Sela, 2001, The optimal allocation of prizes in contests, American Economic Review, 91(3), 542-558.

[31] Moldovanu, B., and A. Sela, 2006, Contest architecture, Journal of Economic Theory, 126(1), 70-96.

[32] Pitchik, C., 2009, Budget-constrained sequential auctions with incomplete information, Games and Economic Behavior, 66(2), 928-949.

[33] Roberson, B., 2006, The Colonel Blotto game, Economic Theory, 29(1), 1-24. 
[34] Siegel, R., 2009, All-pay contests, Econometrica, 77(1), 71-92.

[35] Singh, N., and D. Wittman, 2001, Contests where there is variation in the marginal productivity of effort, Economic Theory, 18(3), 711-744.

[36] Skaperdas, S., 1998, On the formation of alliances in conflict and contests, Public Choice, 96(1-2), 25-42.

[37] Stratmann, T., and F.J. Aparicio-Castillo, 2006, Competition policy for elections: Do campaign contribution limits matter?, Public Choice, 127(1), 177-206.

[38] Stratmann, T., and F.J. Aparicio-Castillo, 2007, Campaign finance reform and electoral competition: Comment, Public Choice, 133, 107-110.

[39] Ujhelyi, G., 2009, Campaign finance regulation with competing interest groups, Journal of Public Economics, 93(3-4), 373-391.

[40] Tan, G., and R. Wang, 1997, Endogenous coalition formation in rivalry, QED Working Paper No. 956, 09-1997, Queen's University.

[41] Tullock, G., 1980, Efficient rent seeking, in: J. Buchanan, R. Tollison, and G. Tullock (eds.), Towards a Theory of the Rent-Seeking Society, Texas A\&M University Press, College Station, 97-112.

[42] Waehrer, K., and M.K. Perry, 2003, The effects of merges in open-auction markets, RAND Journal of Economics, 34(2), 287-304.

[43] Weitsman, Patricia A., 1997, Intimate enemies: the politics of peacetime alliances, Security Studies, 7(1), 156-193. 